\title{
Teaching Modeling and Simulation in Industrial Engineering Technology Pro- grams: A National Survey
}

\section{Dr. Ali Alavizadeh, Indiana University - Purdue University, Fort Wayne}

Dr. Ali Alavizadeh is an Assistant Professor of Industrial Engineering Technology at Purdue University, Calumet (Hammond, IN). Previously, he taught at Indiana University-Purdue University, Fort Wayne (Fort Wayne, Indiana), The George Washington University (Washington, DC), and Morehead State University (Morehead, KY) in the areas of Industrial Engineering Technology, and Engineering Management and Systems Engineering. His industrial experiences include software engineering, systems engineering and analysis, and production optimization for private, governmental, and nongovernmental organizations. His research interests include complex systems modeling and simulation and systems engineering, and their application in healthcare and aerospace.

\section{Dr. Maximo J. Ortega, Indiana Tech}

Dr. Maximo Ortega is an Associate Professor of Industrial and Manufacturing Engineering at Indiana Tech. He is responsible for the Automation Laboratory. Dr. Ortega is a Fulbright Scholar and was a member of the Mexican National Academy of Industrial Engineering. He was a Visiting Assistant Professor at Purdue University from 2001 to 2003. Dr. Ortega earned his Bachelor of Science in Industrial Engineering at the Chihuahua Institute of Technology, a Master in Science in Industrial Engineering at the Cd. Juarez Institute of Technology, a Master in Science in Educative Mathematics at the Research Center for Advanced Studies (CINVESTAV del IPN) and Ph.D. in Industrial Engineering from the State University of New York at Buffalo.

\section{Dr. Maged Mikhail, Purdue University - Calumet}

Dr. Maged B. Mikhail, Assistant Professor, Mechatronics Engineering Technology Ph.D., Electrical Engineering, Tennessee State University, Nashville, Tennessee, August 2013. Dissertation title: "Development of Integrated Decision Fusion Software System For Aircraft Structural Health Monitoring" M.S., Electrical Engineering, Tennessee State University, Nashville, Tennessee, May 2009. Thesis title: "Development of Software System for Control and Coordination of Tasks among Mobile Robot and Robotic Arm." B.S., Electrical Engineering University of El Mina Cairo, Egypt, May 2001. 


\title{
Teaching modeling and simulation in industrial engineering technology programs: A national survey
}

\begin{abstract}
The purpose of this study is twofold: to learn about the extent to which a course on modeling and simulation is being taught/covered in industrial engineering technology programs in the U.S., particularly, at graduate level, and to learn about how such a course was structured and offered in terms of group project, method of delivery, etc. Based on the analyses done on the results of the survey, with exception of one, all the participants mentioned that they offer an undergraduate course. As far as software, there were a variety of simulation software mentioned by the participants such as ARENA and ProModel, to name a few. The respondents also emphasized on the importance of real-life projects and such aspects as team work and long-life learning.
\end{abstract}

Introduction

Discrete-event modeling and simulation provides useful information on how one can modify a system in order to streamline the production flow, decrease waste, remove identified bottlenecks, etc. As Banks ${ }^{[1]}$ states, simulation is "the imitation of the operation of a real-world process or system over time." Furthermore, in designing new systems, a simulation experiment would help designers run various scenarios to select the optimal alternative among the others. In some cases it may be possible to study the real system and to modify it to observe any change in the system output(s), for example, examining the impact of increasing the number of automated check-in kiosks on reducing passengers' waiting time in airports ${ }^{[2]}$. However, in some other situations, for instance, in emergency rooms, it is not an appropriate approach to make changes in the system.

Simulation courses have been part of the Industrial Engineering curriculum since the 90's. Simulation courses have been offered in traditional Industrial Engineering programs; however, it was unknown as to whether such a topic is being covered in the form of a course in Engineering Technology programs at graduate level specifically. Discrete Simulation models may be used as part of other courses (i.e. Production Planning, Design of Experiments, etc.) however, if students are expected to develop their own models, at least a whole course for a full semester would be necessary. The authors believe that it is crucial to teach modeling and simulation in engineering technology particularly, at graduate level. The main reason is that the majority of graduates assume managerial/supervisory positions as they grow in their field and modeling and simulation is a useful technique that helps them make better decision when it comes to update/modify current systems. Two of the authors have experience in teach a graduate-level discrete-event simulation offered in a Master of Science in Technology course. Yet, they would like to learn from the peers on how they could improve their teaching and the courses offered to better serve the students and the regional industry. However, an initial investigation to identify the programs in which such a course is, or has been offered, did result in only few programs in engineering technology. This motivated the authors to learn about those programs that include such a course in their curriculum. 
The goals

The goals of this study is twofold: to learn about the extent to which a course on modeling and simulation is being taught/covered in industrial engineering technology programs in the U.S., and to learn about how the course was structured and offered in terms of group project, method of delivery, etc. In particular, the authors would like to learn whether the graduate programs offer, or have offered, such a course. Moreover, the authors are interested in learning about recommended software packages used by those identified programs.

Methodology

An online survey, including 19 questions, was prepared using Qualtrics and was validated. The survey was then submitted to University's Institutional Review Board, along with necessary documents to obtain the approval prior to conducting the research. The survey was approved to be distributed. The authors consulted the ABET's ${ }^{[3]}$, ASEE's listproc, and the Association of Technology, Management, and Applied Engineering (ATMAE)'s ${ }^{[4]}$ databases to identified the universities in the United States with a program in engineering technology including industrial engineering technology, manufacturing engineering technology, and industrial technology. Also, the request for participation was sent twice to the ASEE's mailing list to reach out to those programs whose name might not be mentioned in those databases. The authors compiled a list of all institutions and contact information of individual faculty members and/or department chairs. The authors invited the identified faculty members to participate in the research by contacting them via e-mail or personal telephone conversation. Upon their acceptance, a consent letter describing the purpose of the research and its goals, along with a link to the online survey were sent. Appendix A includes the questions asked in the online survey.

\section{Data analysis and discussion}

The survey was sent to 23 participants and a total of 6 participants completed the survey. Qualtrics provided a summary of responses to each question and a bar chart that depicts the responses as shown below. What follows is a discussion on the responses received for each question: there was only one program that offers a graduate course on modeling and simulation. The courses were mainly offered in face-to-face format, except for one institution (Figure 1). The graduate course was offered every other semester. Yet, the respondent also stated that it has not been offered.

\begin{tabular}{|c|l|c|c|c|}
\hline$\#$ & Answer & & Response & $\%$ \\
\hline 1 & Undergraduate & 5 & $83 \%$ \\
2 & Graduate & & 1 & $17 \%$ \\
3 & Both & & 0 & $0 \%$ \\
\hline & Total & 6 & $100 \%$ \\
\hline
\end{tabular}




\begin{tabular}{|c|l|c|c|c|}
\hline$\#$ & Answer & Response & $\%$ \\
\hline 1 & Face-to-face & 4 & $67 \%$ \\
\hline 2 & $\begin{array}{l}\text { Online } \\
\text { Hybrid (i.e., a } \\
\text { combination of } \\
\text { face-to-face and } \\
\text { online) } \\
\text { an } \\
\text { undergraduate- }\end{array}$ & 1 & $0 \%$ \\
\hline 4 & $\begin{array}{l}\text { level course is } \\
\text { not offered. }\end{array}$ & 1 & $17 \%$ \\
\hline Total & $100 \%$ \\
\hline
\end{tabular}

Figure 1. Responses to Questions 1 and 2, respectively (Appendix A includes the survey questions).

In response to the question: "What simulation software package(s) do you use?" the respondents used a variety of software packages in their program including ProModel, ARENA, Simio, Flexim, Delmia, and GPSS. In particular, ProModel was used in the graduate-level course.

Table 1 shows how long the course has been offered by those programs (e.g., "How long have you offered the course (undergraduate or graduate)?") The graduate course is being offered for 25 years, while for undergraduate courses offered at other institution, the time period varies.

Table 1. "How long have you offered the course (undergraduate or graduate)?"

$$
\begin{aligned}
& \text { Text Response } \\
& 25 \text { years } \\
& \text { More than } 5 \text { years } \\
& 2 \text { semesters so far } \\
& 10 \text { years } \\
& 16 \text { years } \\
& \text { One year }
\end{aligned}
$$

A final project was mandatory, as mentioned by all participants, except for one intuition, where the course is an undergraduate one. It is done either individually ( 2 institutions) or in group (3 institutions). All the participant stated that the nature of the final project that students do is applied. For example, one participant mentioned that the project "Involves very specifically designing a facility to suppost [support] the fabrication and assembly of a consumer product." Table 2 shows the response to the question: "Please provide your feedback as to how you recommend the course should be offered in terms of method of delivery, topics, software, etc." 
Table 2. "Please provide your feedback as to how you recommend the course should be offered in terms of method of delivery, topics, software, etc."

\section{Text Response}

We have students do three simulation exercises at the undergraduate level, just to get them

exposed to simulation. It isn't until the graduate level, however, that they become somewhat proficient in the use of simulation.

The topics are in the form of lab assignments in a varied field including inventory control, manufacturing process, mom\&pop shop process, office paper trail, and others.

Make students become life-long learners using tutorials, software Helps, team work and external resources (e.g.; YouTube). Plan projects, solve problems and research solutions. The specific software less important than the learning and teamwork process, plus the real-life application of the advanced technologies in an industrial environment.

The first recommendation is of particular interest since it implies that the concept of modeling and simulation is covered at two levels, though there is not an undergraduate course on the subject at that institution. The students learn about the concept of modeling and simulation but as they pursue their master's degree, they specifically learn about the subject matter. Other recommendations came from those institutions that offer an undergraduate course only. Yet, the authors believe that one could implement their recommendations in a graduate course on modeling and simulation, as well.

\section{Conclusion}

In this paper the results of a national survey on the extent to which a course on modeling and simulation is being taught at the U.S. universities were discussed. The results suggested that there are a few graduate programs where a graduate course on modeling and simulation is being offered. Moreover, there are a variety of software packages that are used, such as ARENA and ProModel. All the participants emphasized on the importance of a hands-on approach to teach modeling and simulation with real-world project. The authors believe that such approach should be considered in other courses such as Design of Experiments, and production planning, since engineering technology discipline focuses more on application.

The authors believe that such a subject should be taught at undergraduate and particularly, at graduate level in relevant engineering technology programs such as industrial and manufacturing engineering technology. However, there seem to be few programs that offer, or have offered, a course specifically on modeling and simulation. Out of 82 colleges and universities listed in ATMAE's database and ABET-accredited programs in engineering technology and industrial engineering technology, 23 programs were identified that offer, or have offered, such a course. This could be an indication of programs' lack of interest in offering a course on modeling and simulation. It was beyond the scope of the current study to learn about the possible reasons. Rather, the current study revealed this issue which could be addressed in a follow-up study.

Furthermore, the authors believe that discrete-event simulation models may be used as part of other courses (i.e. Production Planning, Design of Experiments, etc.); however, if students are expected to develop their own models, at least a whole course for a full semester would be 
necessary. Ideally they should be introduced to simulation at the undergraduate level. If they are skilled at developing simulation models they then would be able to test improvements in the layout or inventory policies, etc. before they are implemented. At the graduate level the technique is relevant because provides a very efficient way to test new approaches and explore the impact of different production scenarios.

\section{Reference}

[1]. Banks, J. (1998). Handbook of simulation: Principles, Methodology, Advances, Applications, and Practice. Danvers, MA: John Wiley \& Sons, Inc.

[2] Kelton, W. D., Sadowski, R. P., \& Sturrock, D. T. (2007). Simulation with ARENA (4 ${ }^{\text {th }}$ ed.). New York, NY: Mc Graw-Hill.

[3] Accreditation Board for Engineering and Technology, Inc. (2014, June, $11^{\text {th }}$ [Online]. Available: http://main.abet.org/aps/Accreditedprogramsearch.aspx

[4] The Association of Technology, Management, and Applied Engineering (ATMAE) (2016, January 22 $2^{\text {nd }}$ [Online]. Available: http://www.atmae.org/ 


\title{
Appendix A: The survey questions
}

\author{
What is the level of the course? \\ Undergraduate \\ Graduate \\ Both
}

How is the undergraduate course being offered?

Face-to-face

Online

Hybrid (i.e., a combination of face-to-face and online)

an undergraduate-level course is not offered.

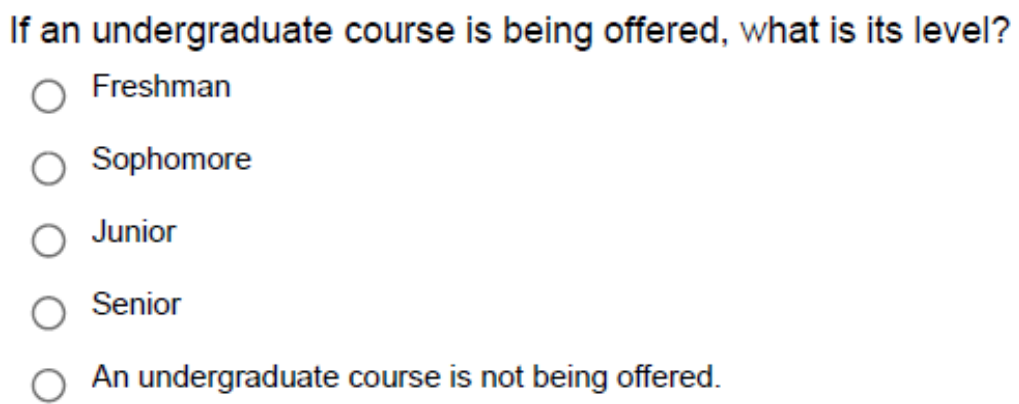

How is the graduate course being offered?

Face-to-face

Online

Hybrid (i.e., a combination of face-to-face and online)

a graduate-level course is not offered.

How often is the course(s) being offered?

\begin{tabular}{l|ccc} 
& Every semester & Every other semester & No regular frequency \\
Undergraduate & $\square$ & $\square$ & $\square$ \\
Graduate & $\square$ & $\square$ & $\square$
\end{tabular}


If you chose "Others" in previous question, please explain how often the course(s) is being offered.

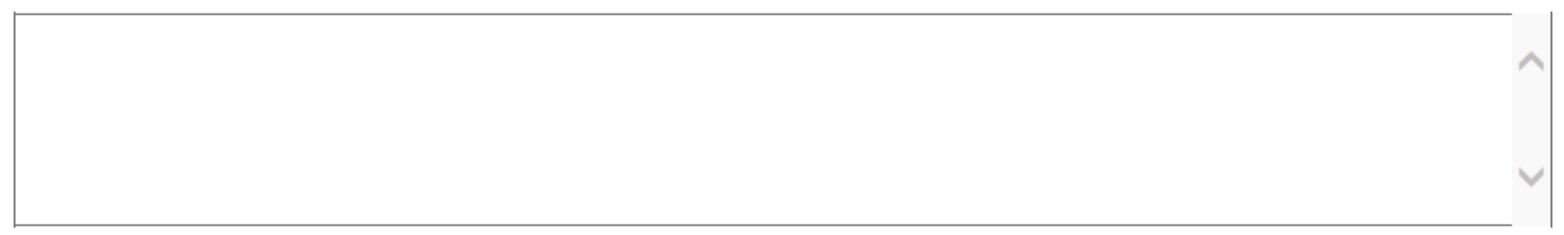

What is the typical weekly schedule of the course(s)?

\begin{tabular}{l|ccccc} 
& Twice a Week & Thrice a Week & $\begin{array}{c}\text { The course is not } \\
\text { being offered }\end{array}$ & \\
\hline Undergraduate & 0 & 0 & 0 & $\bigcirc$ \\
Graduate & 0 & 0 & $\bigcirc$ & 0
\end{tabular}

If you chose "Others" in previous question, please explain what the typical weekly schedule of the course(s) is. Otherwise, please proceed to next question.

What percentage of your course is dedicated to the theory of simulation (probability distributions, random numbers, statistical analysis, etc.) ?

Less than $25 \%$

Between $25 \%$ and $50 \%$

Between $50 \%$ and $75 \%$

More than $75 \%$

What percentage of your course is dedicated to learning a specific software tool?

Less than $25 \%$

Between $25 \%$ and $50 \%$

Between $50 \%$ and $75 \%$

More than $75 \%$ Click to write Choice 4 
What simulation software package(s) do you use?

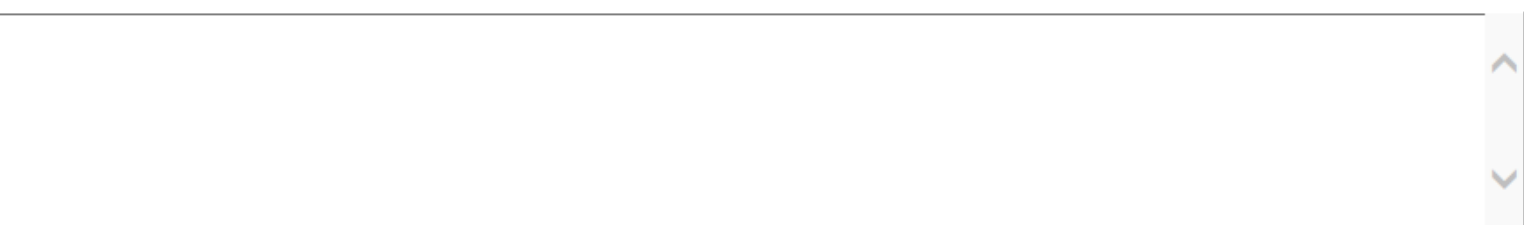

What are the strength of the simulation software package(s) you use?

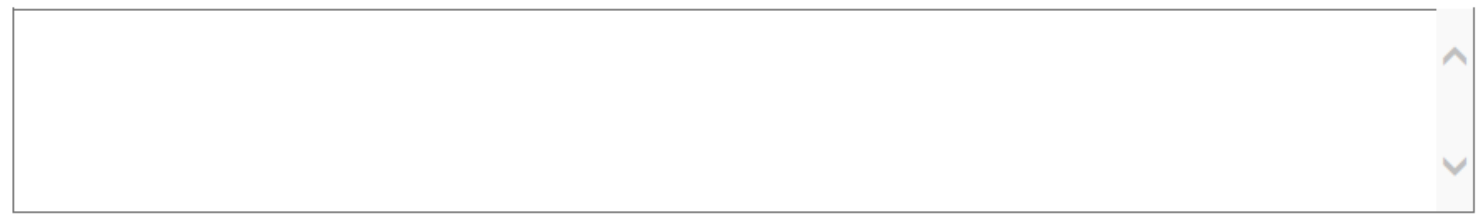

What are the weaknesses of the simulation software package(s) you use?

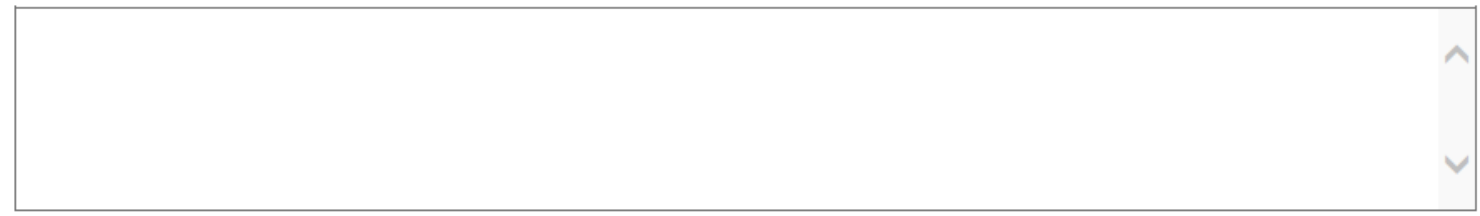

How long have you offered the course (undergraduate and graduate)?

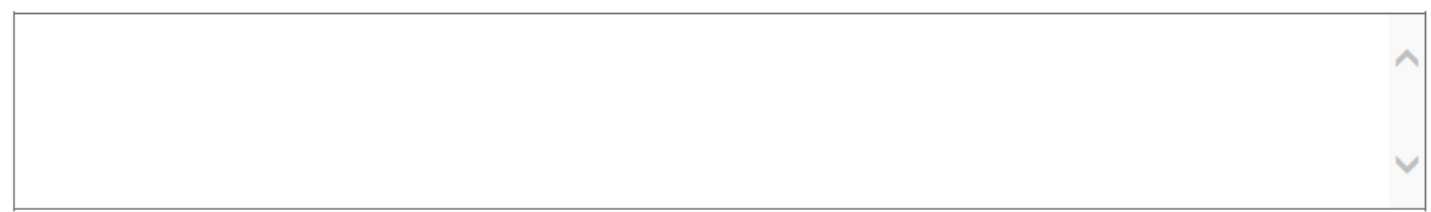

Is a final project a course requirement for students (either graduate or undergraduate)?

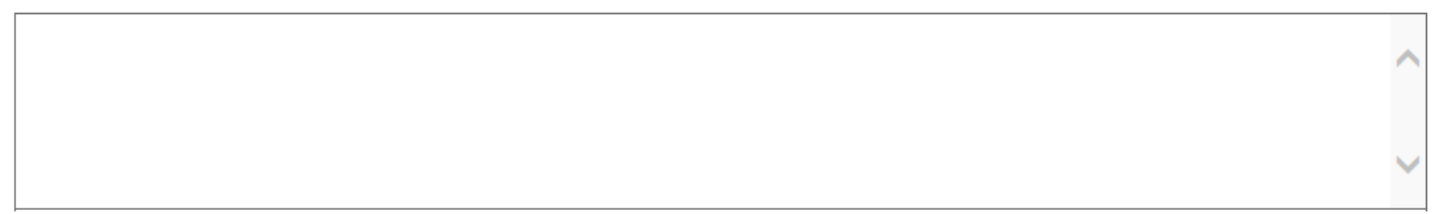

Is a final project a group project or an individual project (either graduate or undergraduate)? 
For both graduate and undergraduate levels, is the nature of the final project more applied or theoretical? Please explain.

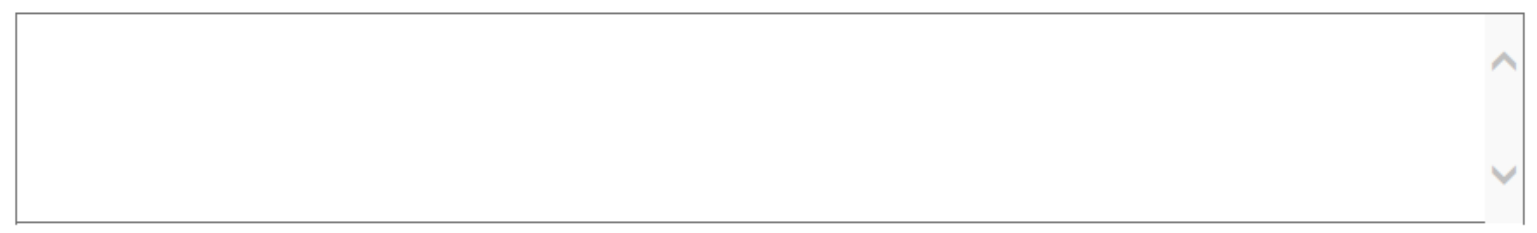

What feedback do you receive from your advisory committee and/or the regional companies regarding the applicability and usefulness of the course?

What does your advisory committee and/or the regional companies suggest as far as the course improvement and topics to be covered?

Please provide your feedback as to how you recommend the course should be offered in terms of method of delivery, topics, software, etc. 